\title{
Inhibition of the Adenylylation of Liver Plasma Membrane-Bound Proteins by Plant and Mammalian Lectins
}

\author{
Estcban San Josí:". Eduardo Vil..alobo". Hans-J. Gabius ${ }^{\mathrm{b}}$ and Antonio Vil...alobo" \\ "Instituto de Investigaciones Biomédicas. Consejo Superior de Investigaciones Científicas. Madrid. Spain and \\ "Institut für Pharmazcutische Chemie der Philipps-Universität. \\ Abteilung Glykobiochemic und Angewandte Tumorlektinologic. Marburg. Germany
}

(Received 6 August 1992)

Summary: Liver plasma membrane contains four major (130-kDa, 120-kDa, 110-kDa and 100-kDa) sialic acid-containing glycopolypeptides that are able to undergo adenylylation, as well as phosphorylation (San José et al. (1990) J. Biol. Chem. 265; 2065320661). To gain insight into the regulation of these processes, lectins are employed to probe the extent of influence of their interaction with membrane fractions for these reactions. We demonstrate that the $\beta$ galactoside-specific lectins from bovine heart and mistletoe at low concentrations inhibit the adenylylation of this set of plasma membrane glycopolypeptides. The extent of phosphorylation of these polypeptides is also reduced although to a lesser degree. Concanavalin $\mathrm{A}$, too, inhibits the adenylylation of the plasma membrane glycopolypeptides, although higher concentrations of this lectin were required, whereas wheat germ lectin has only a very small inhibitory effect. The adenylylable polypeptides were isolated by concanavalin A-agarose chromatography upon elution with mannose. In agreement with this result, control experiments with a panel of neoglycoproteins indicate that mannose residues appear to be required for the concanavalin A-induced inhibition of the adenylylation. Neoglycoproteins containing mannose 6-phosphate, lactose, fucose, or sialic acid instead of mannose lack the ability to protect the adenylylation from the inhibitory action of concanavalin $\mathrm{A}$. In contrast, none of the above-mentioned neoglycoproteins, nor asialofetuin, nor galactose-containing saccharides protect the adenylylation against the inhibitory effect of both the mistletoe and bovine heart lectins, emphasizing the importance of either high affinity carbohydrate ligands in the overall process, or other ligand sites for the lectins beside carbohydrates to affect the regulation of the adenylylation system.

Key terms: Adenylylation, phosphorylation, lectins, glycoproteins.

A great majority of integral plasma membrane proteins from eukaryotic cells are glycosylated. The glycosylation of plasma membrane proteins should not just be considered as a biologically inert structural addition to the protein backbone. Conversely, important cellular functions, such as intercellular recogni-

\footnotetext{
Abbreviations:

Hepes, 4-(2-hydroxyethyl)-1-piperazinethanesulfonic acid; SDS, sodium dodecyl sulfate; PMSF, phenylmethanesulfonyl fluoride: ML-I, mistletoe lectin I; 14k-bh. bovine heart $14 \mathrm{kDa}$ lectin: ConA, concanavalin A; WGA, wheat germ lectin (agglutinin); Lac, lactose; $\alpha$-Mel, $\alpha$-D(+)-melibiose (6-O- $\alpha$-D-galactopyranosyl-D-glucose): Man, mannose: Gal. D(+)-galactose; 4- $\beta$-Gal-Man. 4-O- $\beta$-galactopyranosyl-D-mannopyranosc: 6- $\beta$-Gal-Gal, 6-O- $\beta$-galactopyranosyl-D-galactose; 4 - $\alpha$-Gal-Gal, 4-O- $\alpha$-1)-galactopyranosyl-D-galactopyranose; $3-\beta$-Gal-Ara, 3-O- $\beta$-1)-galactopyranosyl-D-arabinose: $4-\beta$-Gal-Fru, 4- $O-\beta$-D-galactopyranosyl-1)fructofuranose (lactulose): ASF. asialofetuin; Lac-BSA, neoglycoprotein containing $\beta$-lactose; Man-BSA, neoglycoprotein containing $\alpha$-D-mannose; Man-6-P-BSA. ncoglycoprotein containing $\alpha$-D-mannose-6-phosphatc: Fuc-BSA, neoglycoprotein containing $\alpha$-L-fucose; Sia-BSA, neoglycoprotcin-containing sialic acid; BSA, bovine serum albumin; TGF- $\gamma 2$. transforming growth factor- $\gamma 2$; poly(Glu:Tyr), co-polymer of glutamic acid and tyrosinc.
} 
tion and cell adhesion processes, certain hormonal actions, and immunological recognition events can be mediated by the carbohydrate residues of proteins. The diverse sequences and complex branching of the carbohydrate residues in glycoproteins are likely to contain important informational clues that have to be deciphered for appropriate action of soluble or membrane-bound ligands. Suitable ligands may well be lectins that play a physiological role in the cell and/or can be involved in pathogenic actions ${ }^{[1-3]}$.

Lectins were first recognized as proteins from plants by their characterized ability to bind to the carbohydrate residues of glycoconjugates ${ }^{[+.5]}$. The observation that lectins are present in animal cells ${ }^{[5.6]}$ has undoubtedly contributed to the realization that lectins. in addition to being useful biochemical tools ${ }^{[7]}$, are involved in important cellular functions.

Lectins mediate their cellular actions by yet unknown signal transduction mechanisms, which function between their plasma membrane-bound glycoprotein receptor(s) and intracellular target(s). Regulation of response to hormones and gangliosides is supposed to encompass such protein-carbohydrate recognition mechanisms ${ }^{[8-10]}$. The reversible interconversion of enzymes is at the crossroads of signal transduction in multiple cellular systems. To investigate the role of this type of molecular recognition event, we have explored the action of a mammalian lectin, namely the $\beta$-galactoside-specific lectin of $14-\mathrm{kDa}$, as well as three plant lectins on the function of a recently described $^{[11]}$ rat liver plasma membrane-bound adenylylation system(s). In this report, we present evidence that the adenylylation of four major plasma membrane-bound glycopolypeptides can be inhibited by these lectins. Remarkably, the phosphorylation of the same polypeptides is affected by lectins to a far lesser extent. No significant effects of these lectins on the phosphorylation of other liver plasma membrane proteins were detected, when crude or further purified membrane fractions were analysed.

\section{Materials and Methods}

\section{Chemicals}

The radiolabeled compounds [ $\gamma-3$ P]ATP (triethylammonium salt) $\left.3000 \mathrm{Ci} \times \mathrm{mmol}^{-1}\right)(1 \mathrm{Ci}=37 \mathrm{GBq}),\left[\alpha-^{32} \mathrm{P}\right] \mathrm{ATP}$ (tetral triethylammonium] salt $\left.\left(3000 \mathrm{Ci} \times \mathrm{mmol}^{-1}\right)\right)$ were purchased from New England Nuclear and $X$-Omat AR $x$-rav blue-sensitive films were from Eastman Kodak. Concanavalin A. concanavalin A-agarose, wheat germ lectin, 4-nitrophenyl glycosides. ATP (sodium salt). lactose ( $\alpha$ and $\beta$ enantiomeric forms), $\mathrm{D}(+)$-mannose, $\alpha$-D $(+)$-melibiose. $\mathrm{D}(+)$-galactose, $4-O$ - $\beta$-galactopyranosyl-D-mannopyranose, 6-O$\beta$-galactopyranosyl-D-galactosc. $4-O-\alpha$-D-galactopyranosyl-D-galactopyranose, 3-O- $\beta$-1D-galactopyranosyl-D-arabinose, and 4-O- $\beta$-Dgalactopyranosyl-D-fructofuranose were obtained from Sigma.
Hepes and divinyl sulfone were from Merck. carbohydrate-free bovine serum albumin used for synthesis of neoglycoproteins was from Biomol. Sepharose $4 B$ from Pharmacia, and molecular mass standards for electrophoresis were purchased from. Bio-Rad. All other chemicals used in this work were of analytical grade.

\section{Preparation of liver plasma membrane fractions}

Crude and further purified liver plasma membrane fractions from male Sprague-Dawley albino rats (250-300 g) were prepared following the method of Brown et al. ${ }^{[12]}$ as modified by us ${ }^{[11.13]}$. The enrichment we obtained in plasma membrane enzy'matic markers $\left(\overline{5}^{\prime}-\right.$ nucleotidase. alkaline phosphatase or phosphodiesterase), with respect to the crude homogenate was 15 -fold \pm 1 (average $\pm S E$ ) in the crude fractions ( 27 preparations) and 41 -fold \pm 6 in the further purified fractions ( 10 preparations). The crude fractions ( 20 to 50 $\mathrm{mg}$ of protein per preparation) were obtained from the first sucrose gradient centrifugation. and the further purified fractions ( 5 to 10 $\mathrm{mg}$ of protein per preparation) were the light fractions obtained from the second sucrose gradient centrifugation. Crude plasma membrane fractions were used for most of the adenylylation experiments, whereas the further purified plasma membrane fractions were used for most of the phosphorylation experiments. because the extent of phosphorylation of the polypeptides under study was better observed in the further purified membranes. The legends to the figures give detailed information on which type of preparation has been used in each series of experiments.

\section{Adenylylation and phosphorylation experiments}

Unless indicated otherwise, our assays were carried out as follows: an adequate amount of plasma membranes (28 to $115 \mu \mathrm{g}$ of protein) was incubated at $37^{\circ} \mathrm{C}$ for $1 \mathrm{~min}$ (phosphorylation experiments) or 5 min (adenylylation experiments) in a total volume of 100 or 200 $\mu l$ of a medium containing $20 \mathrm{~mm} \mathrm{Na-Hepes} \mathrm{(pH} \mathrm{7.4),} 0.1 \%(\mathrm{w} / \mathrm{v})$ Triton X-100, and $10 \mu \mathrm{M}$ of either [ $\left.\gamma_{-}{ }^{32} \mathrm{P}\right] \mathrm{ATP}(2-3 \mu \mathrm{Ci})$ (phosphorylation experiments) or $\left[\alpha-{ }^{32} \mathrm{P}\right]$ ATP $(1.5-4 \mu \mathrm{Ci})$ (adenylylation experiments). Triton X-100 was added to permeabilize membrane vesicles, in order to allow the binding of ligands to both sides of the membrane. Some phosphorylation experiments were performed in the presence of $6 \mathrm{mM} \mathrm{MgCl}_{2}$. Lectins were incubated with the membranes at $4{ }^{\circ} \mathrm{C}$ for 20 to $30 \mathrm{~min}$ prior to the assay to allow binding to membrane ligands. Some of the adenylylation experiments were performed in the presence of $1 \mathrm{~mm}$ EDTA, since this metal-chelating agent yields 20 to 40 -fold increases in the adenylylation level due to the inhibition of ATPases, therefore increasing the availability of ATP for the adenylylation process. The reaction was stopped by addition of ice-cold trichloroacetic acid to a final concentration of $10 \%(\mathrm{w} / \mathrm{v})$, and the pellet of precipitated proteins was first ncutralized with a minimum volume of $1.25 \mathrm{MTris} / \mathrm{HCl}(\mathrm{pH}$ 8.8 ), the solution was gently stirred with a glass-rod to dissolve the protein precipitate and processed for electrophoresis and autoradiography. We found that the inhibitory action of lectins was not significantly affected by the concentration of plasma membrane protein in the assay system within the range used.

\section{Sinthesis of neoglycoproteins}

Sugar-free bovine serum albumin was used as carrier protein for the attachment of glycosides and coupled to the p-isothiocyanate derivatives of p-aminophenyl glycosides to yield neoglycoproteins containing on average $30 \pm 4$ carbohydrate moieties per carrier molecule, as described in detail elsewhere ${ }^{(1+1)}$.

\section{Purification of lectins from mistletoe and bovine heart}

Fractionation of extracts from dried mistletoe leaves and from bovine heart on lactose-Sepharose $4 \mathrm{~B}$, obtained by divinyl sulfone activation of the matrix and subsequent coupling of the ligand, elution by $0.3 \mathrm{M}$ lactose, and quality controls of the purified lectins have been described in detail previously ${ }^{[15]}$. 


\section{Preparation of lectin-bearing matrices}

Divinyl sulfone-activated Sepharose $4 \mathrm{~B}(10 \mathrm{~m} l)$ was incubated with $3 \mathrm{mg}$ lectin dissolved in $8 \mathrm{ml}$ of $0.2 \mathrm{~N} \mathrm{Na} \mathrm{HPO}_{4} / \mathrm{KH}_{2} \mathrm{PO}_{4}(\mathrm{pH} 8.6$ ), $0.9 \%(w / v) \mathrm{NaCl}$. for $12 \mathrm{~h}$ at $+{ }^{\circ} \mathrm{C}$. The bovine heart lectin was stabilized by carboxymethylation prior to coupling according to Powell and Whitney ${ }^{[16]}$. The coupling yicld was determined by the dye-binding assay with albumin as standard ${ }^{[17]}$, and the capacity of the matrix was checked with asialofetuin, as described recently ${ }^{[1 s]}$.

\section{Affinity chromatography with immobilized mistletoe} and bovine heart lectins

Purified plasma membranes ( $43 \mathrm{mg}$ of protein) were solubilized in a medium containing $20 \mathrm{~mm}$ Tris $/ \mathrm{HCl}(\mathrm{pH} 7.8) .0 .5 \mathrm{M} \mathrm{NaCl} .4 \mathrm{~mm} 2$ mercaptoethanol. 2mM EDTA. 100mm lactose. $0.5 \%(w / v)$ Triton $X-100.0 .1 \%(w / v)$ Na-deoxycholate. and protease inhibitors (0.1 mM PMSF. $5 \mu \mathrm{g} \times \mathrm{m} l^{-1}$ leupeptin. and $5 \mu \mathrm{g} \times \mathrm{ml}^{-1}$ antipapain). After dialysis overnight against $20 \mathrm{~mm}$ Tris/ $\mathrm{HCl}(\mathrm{pH} 7.8), 150 \mathrm{mM}$ $\mathrm{NaCl}, 2 \mathrm{~mm}$ EDTA. 2mM 2-mercaptoethanol, and $0.02 \%(w / v)$ Triton $\mathrm{X}-100$. to remove the sugar, the extract (half volume each) was passed through the mistletoe lectin I-Sepharose or the bovine heart $14-\mathrm{kDa}$ lectin-Sepharose columns $(5-\mathrm{m} /$ bed volume containing 280 $\mu \mathrm{g}$ of protein $\left.\times \mathrm{m} l^{-1}\right)$ equilibrated with $20 \mathrm{mM}$ Tris $/ \mathrm{HCl}(\mathrm{pH} 7.8)$, $150 \mathrm{~mm} \mathrm{NaCl}, 1 \mathrm{~mm}$ dithiothreitol, and $0.02 \%(\mathrm{w} / \mathrm{v})$ Triton $X-100$. After extensive washing with this buffer the elution was performed with the same buffer containing $0.3 \mathrm{M}$ lactose. The eluted fractions were dialysed first against $20 \mathrm{~mm}$ Tris/ $\mathrm{HCl}(\mathrm{pH} 7.8)$. containing $2 \mathrm{mM}$ EDTA. 4m 2-mercaptoethanol. and $0.05 \%$ (w/v) Triton X-100, and thereafter against the same buffer containing only $7.5 \mathrm{~mm}$ Tris/ $\mathrm{HCl}$ ( $\mathrm{pH}$ 7.8). After chloroform extraction to remove the Triton $\mathrm{X}-100$. the samples were lyophilized and stored at $-60^{\circ} \mathrm{C}$ until used. The resin with immobilized mistletoe lectin yielded $65 \mu \mathrm{g}$ of protein, and the bovine heart lectin-Sepharose column $105 \mu \mathrm{g}$ of protein according to the dye-binding assay.

\section{Concanavalin A-agarose chromatography}

Purified plasma membranes (5 to $7.5 \mathrm{mg}$ of proteins) were solubilized for $10 \mathrm{~min}$ at $4{ }^{\circ} \mathrm{C}$ in 1.5 to $3 \mathrm{~m} /$ of a medium containing $25 \mathrm{~mm}$ Na-Hepes (pH 7.4), and $1 \%(w / v)$ Triton X-100, and ccntrifuged at $100000 \times g_{\max }$ for $15 \mathrm{~min}$. The resulting supernatant was passed through a concanavalin A-agarose column $(5 \mathrm{~m} /$ bed volume containing $14 \mathrm{mg}$ of protein $\times \mathrm{ml}^{-1}$ ), equilibrated with $25 \mathrm{mM} \mathrm{Na-}$ Hepes ( $\mathrm{pH} 7.4$ ). $1 \mathrm{~mm} \mathrm{CaCl}$ (when added), and $1 \%(w / v)$ Triton $\mathrm{X}-100$. Thereafter, the bound proteins were eluted with a buffer containing $25 \mathrm{~mm} \mathrm{Na-Hepes} \mathrm{(pH} \mathrm{7.4),} 1 \%$ (w/v)Triton X-100, 1mM $\mathrm{CaCl}_{2}$ (when added), and $50 \mathrm{~mm}$ mannose. The eluted fractions $(0.8$ $\mathrm{m} l$ each) were collected and stored at $-70^{\circ} \mathrm{C}$ until use.

\section{Other analytical procedures}

Slab gel electrophoresis (30 to $70 \mu \mathrm{g}$ of protein per lane) was performed according to the method of Laemmli ${ }^{[19]}$ at $12 \mathrm{~mA}$ overnight in linear gradient $5-20 \%(\mathrm{w} / \mathrm{v})$ polyacrylamide gels in the presence of $0.1 \%(w / v)$ SDS at $\mathrm{pH} 8.3$. Alternatively, slab gels with $10 \%$ (w/v) polyacrylamide in the running gel and $3 \%(w / v)$ in the stacking gel were used. The gels were stained with Coomassie Brilliant Blue $\mathrm{R}-250$, and dried under vacuum at $70^{\circ} \mathrm{C}$ on Whatman $3 \mathrm{MM}$ filter paper. Alternatively, silver staining ${ }^{[20]}$ was employed for visualization of protein bands when less than $10 \mu \mathrm{g}$ were applied per lane. The $x$-ray films were exposed in the dark at $-20^{\circ} \mathrm{C}$ for appropriate periods of time ( 1 to 5 days) to obtain autoradiographs. The intensities of the labeled bands on the autoradiographs were measured in a scanning photodensitometer. We demonstrated that the optical densities of the labeled bands in the autoradiographs were linearly proportional to the amount of ${ }^{32} \mathrm{P}$ bound to the proteins in the experimental conditions used.

The method of Lowry et al. ${ }^{[21]}$ was generally used to determine protein concentrations after precipitating the proteins with $10 \%(\mathrm{w} / \mathrm{v})$ trichloroacetic acid, using bovine serum albumin as a standard, the only exception being the determination of the amount of protein in the eluted fractions from the lectin chromatography columns with the dy'e-binding assay of Redinbaugh and Campbell ${ }^{[1]}$

\section{Results and Discussion}

\section{Effects of lectins on the adenylylation of plasma membrane-bound glycoproteins}

We have previously demonstrated that the incubation of isolated rat liver plasma membrane fractions with $\left[\alpha{ }^{32} \mathrm{P}\right]$ ATP or $\left[2,5^{\prime}, 8{ }^{3} \mathrm{H}\right] \mathrm{ATP}$ results in the labeling of four major glycopolypeptides of $130-\mathrm{kDa}, 120$ $\mathrm{kDa}, 110-\mathrm{kDa}$ and $100-\mathrm{kDa}^{[11]}$. This labeling represents the adenylylation of these proteins. Furthermore, we have demonstrated that this adenylylation is a reversible process, and that the $120-\mathrm{kDa}$ and 110 $\mathrm{kDa}$ polypeptides form a heterodimer linked by disulfide bridge(s) ${ }^{[11]}$. In addition, we demonstrated the presence of a $86-\mathrm{kDa}$ phosphodiesterase in these membranes that forms a catalytic intermediate ${ }^{[1]]}$.

We have suggested that the adenylylation of these polypeptides probably represents posttranslational modifications of a plasma membrane system(s) that possibly plays a regulatory role of yet unknown nature $^{[11]}$. It is interesting to refer to prokaryotes, where several enzymes have been described as being regulated by adenylylation ${ }^{[22-27]}$. However, there is no definitive information available about similar regulatory systems in eukaryotic cells.

While attempts to clarify the nature of the adenylylated proteins are currently being undertaken, elucidation of the regulation of this type of modification similarly warrants attention. To initiate the study of this aspect, we focused on a class of proteins that can specifically interact with the carbohydrate part of membrane glycoproteins which are adenylylated, namely lectins. Lectins are supposed to be involved in biosignaling processes, as emphasized by their induction of mitogenesis upon binding to the membrane of responsive cells ${ }^{[5]}$. In this study we used a mammalian $\beta$-galactoside-specific $14-\mathrm{kDa}$ lectin of rather ubiquitous nature ${ }^{[28.29]}$ isolated from bovine heart, as well as several plant lectins.

In Fig. 1 (panel A) the $\left[\alpha-{ }^{32} \mathrm{P}\right] \mathrm{ATP}$-labeled patterns of the plasma membrane polypeptides in the absence (none) and presence of wheat germ lectin (WGA), concanavalin A (ConA), mistletoe lectin I (ML-I), and the $14-\mathrm{kDa}$ bovine heart lectin (14k-bh) are presented. A strong inhibition of the adenylylation of the $130-\mathrm{kDa}, 120-\mathrm{kDa}, 110-\mathrm{kDa}$ and $100-\mathrm{kDa}$ polypeptides in the presence of mistletoe and bovine heart lectins, and to a lesser extent in the presence of concanavalin $\mathrm{A}$ was observed. In comparison, wheat germ lectin exhibits a slight inhibitory effect. As can 
A

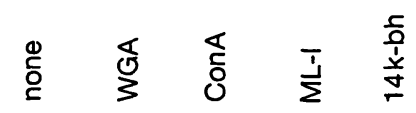
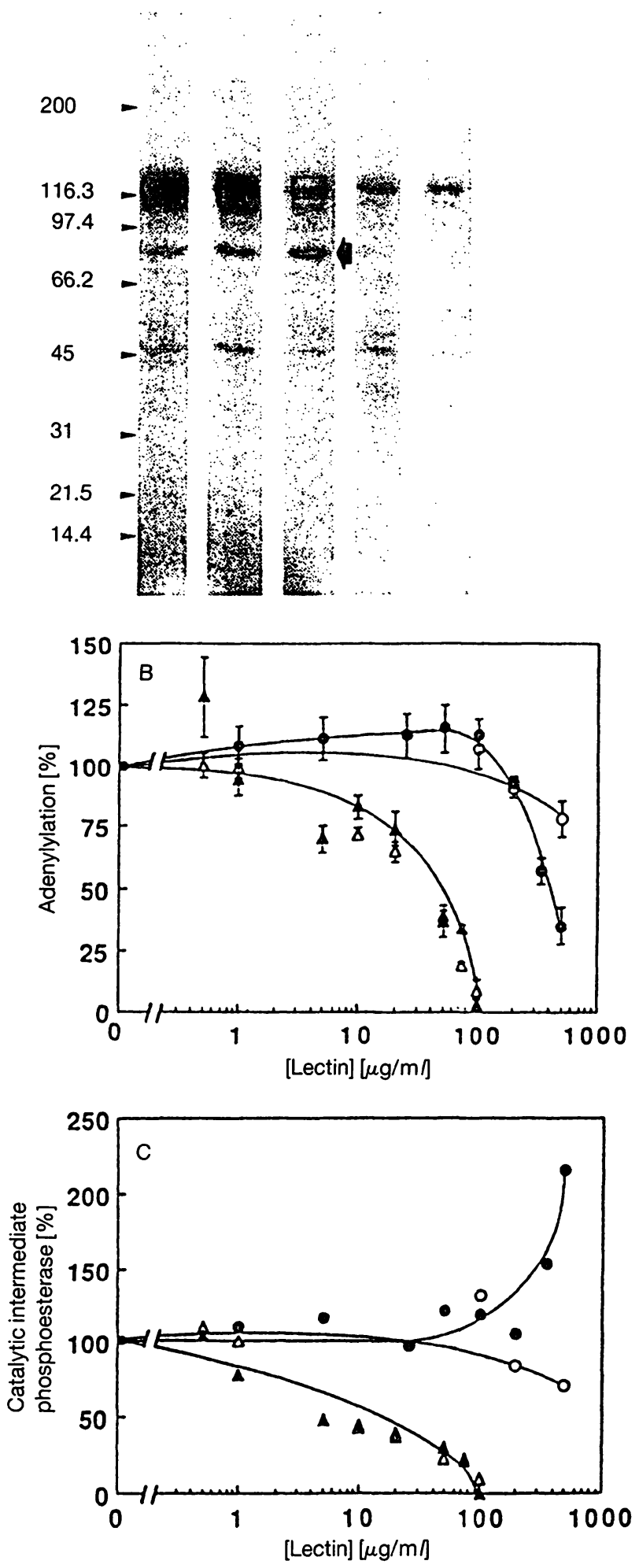

be deduced from Fig. 1, mistletoe and bovine heart lectins inhibit the formation of the catalytic intermediate of the $86-\mathrm{kDa}$ phosphodiesterase. On the contrary, concanavalin A induces a significant increase in the level of this intermediate (see arrow).
Fig. 1. Effects of concanavalin A. and wheat germ. mistletoe, and bovine heart lectins on the adenylylation of the $130-\mathrm{kDa}$. $120-k D a$. $110-k D a$ and $100-k D a$ polypeptides. and on the formation of the catalytic intermediate of the $86-k$ pa phosphodiesterase.

(Panel A) Crude plasma membranes ( $90 \mu \mathrm{g}$ of protein) were incubated in the assays at $37^{\circ} \mathrm{C}$ for $5 \mathrm{~min}$ in $100 \mu \mathrm{l}$ of a medium containing $20 \mathrm{~mm}$ Na-Hepes (pH 7.4), $0.1 \%$ (w/v) Triton X-100 $10 \mu \mathrm{M}\left[\alpha-{ }^{32} \mathrm{P}\right] \mathrm{ATP}$, and the indicated amounts of the following lectins: $100 \mu \mathrm{g} \times \mathrm{m} l^{-1}$ of wheat germ lectin (WGA). $100 \mu \mathrm{g} \times$ $\mathrm{m} l^{-1}$ of concanavalin $\mathrm{A}($ ConA $), 87 \mu \mathrm{g} \times \mathrm{m} l^{-1}$ of mistletoe lectin I (ML-I), or $87 \mu \mathrm{g} \times \mathrm{m} l^{-1}$ of the 14-kDa bovine heart lectin (14k-bh). A control without added lectins is also presented (none). The reaction was stopped by addition of $10 \%(\mathrm{w} / \mathrm{v})$ icecold trichloroacetic acid (final concentration) and the precipitated protcins were processed for clectrophoresis and autoradiography as described in Materials and Methods. (Panels B and $C$ ) Plots representing the action of different concentrations of lectins on the average adenylylation of the $130-\mathrm{kDa} .120$ $k D a .110-k D a$ and 100-kDa polypeptides (panel B), and on the formation of the catalytic intermediate of the $86-\mathrm{kDa}$ phosphodicsterase (panel C) are presented. Concanavalin A. (filled circles): wheat germ lectin (open circles), mistletoe lectin I (open triangles), and the $14-\mathrm{kDa}$ bovine heart lectin (filled triangles) The assays were carried out as above except for alterations in the amount of plasma membranc protein: $115 \mu \mathrm{g}$ (filled circles). $115 \mu \mathrm{g}$ (open circles), $90 \mu \mathrm{g}$ (filled triangles), $90 \mu \mathrm{g}$ (open triangles).

We do not yet know whether the $86-\mathrm{kDa}$ phosphodiesterase intervenes in the deadenylylation of the $130-\mathrm{kDa}, 120-\mathrm{kDa}, 110-\mathrm{kDa}$ and $100-\mathrm{kDa}$ polypeptides, although this is a reasonable proposition. The effect of concanavalin A on the adenylylation process could, in this case, be explained by the activation of the phosphodiesterase. This activation results in a deadenylylation of the higher molecular mass adenylylated protein substrates. In contrast, the same interpretation could definitely not be applied to the analysis of the effects of mistletoe or bovine heart lectins, since their inhibitory action on the adenylylation process is not accompanied by an increase in the catalytic intermediate of the $86-\mathrm{kDa}$ phosphodiesterase (see Fig. 1 panel A).

While this series of experiments used a fixed amount of lectins, Fig. 1 (panel B) presents a plot of the inhibitory effects of the different lectins on the adenylylation of the $130-\mathrm{kDa}, 120-\mathrm{kDa}, 110-\mathrm{kDa}$ and $100-$ $\mathrm{kDa}$ polypeptides as a function of the concentrations of lectins in the assay system. We can calculate an apparent $K_{\mathrm{i}}$ of approximately $40 \mu \mathrm{g} \times \mathrm{m} l^{-1}$ for both $\beta$ galactoside-specific lectins, the mistletoe lectin and the bovine heart lectin. The apparent $K_{\mathrm{i}}$ for concanavalin A was approximately $400 \mu \mathrm{g} \times \mathrm{ml}^{-1}$. In contrast, concentrations as high as $500 \mu \mathrm{g} \times \mathrm{ml}^{-1}$ of 
wheat germ lectin do not inhibit more than $20 \%$ the adenylylation of these polypeptides. Therefore, the failure of wheat germ lectin to exert a significant effect on the adenylylation suggests that binding to accessible $\mathrm{N}$-acetylglucosamine or $\mathrm{N}$-acetylneuraminic acid moieties in glycoconjugates is not too relevant for the net adenylylation process.

We also present in Fig. 1 (panel C) the effects of these lectins on the catalytic intermediate of the $86-\mathrm{kDa}$ phosphodiesterase. It can be observed that both, mistletoe and bovine heart lectins are strong inhibitors of the phosphodiesterase. We calculate an apparent $K_{\mathrm{i}}$ of approximately $10 \mu \mathrm{g} \times \mathrm{ml}^{-1}$ for both lectins. In contrast, $500 \mu \mathrm{g} \times \mathrm{m} l^{-1}$ of wheat germ lectin only inhibits the formation of this catalytic intermediate by $25 \%$. With respect to concanavalin $\mathrm{A}$, an increase in the level of this intermediate of more than 2-fold is detectable by addition of up to $500 \mu \mathrm{g} \times \mathrm{ml}^{-1}$ to the assay.

\section{Mannose residues are involved in the concanavalin A-mediated inhibition of the adenylylation process}

Caution needs to be exercised in the interpretation of lectin binding, because such proteins can well have different domains, enabling them to bind to different types of ligands ${ }^{[5.30]}$. To obtain evidence for the nature of the carbohydrate residues from the adenylylation system involved in the interaction with lectins, chemically glycosylated carrier proteins are used as probes.

It is well known that concanavalin A recognizes mannose residues in glycoproteins. Therefore, it was consistent to find that from a panel of such tools only the neoglycoprotein containing mannose residues effectively prevents the concanavalin A-induced inhibition of the adenylylation process (see Fig. 2). The effect of these substances on the concanavalin A-induced activation of the phosphodiesterase, however, seems to be less clear-cut, since, even in the presence of mannosylated albumin, activation was measurable.

Surprisingly, the activation of the $86-\mathrm{kDa}$ phosphodiesterase is affected by neoglycoproteins carrying fucose or mannose-6-phosphate residues, although these substances are notably ineffective in preventing the inhibition of adenylylation. None of the neoglycoproteins used inhibits the adenylylation of the polypeptides under study (results not shown).

We have also observed that asialofetuin (fetuin that is chemically depleted of sialic acid residues) prevents the inhibitory action of concanavalin A on the adenylylation process (see Fig. 2). This protective effect could be explained by the accessibility of mannose residues in this glycoprotein and the subsequent competitive binding to concanavalin A.
We have also demonstrated that a fraction of the adenylylable polypeptides bind to concanavalin Aagarose in the absence as well as in the presence of calcium ions, and are eluted in the presence of mannose (results not shown).

To assess the enzymatic activities of the purified material, we have carried out phosphorylation experiments using the fractions eluted with mannose from
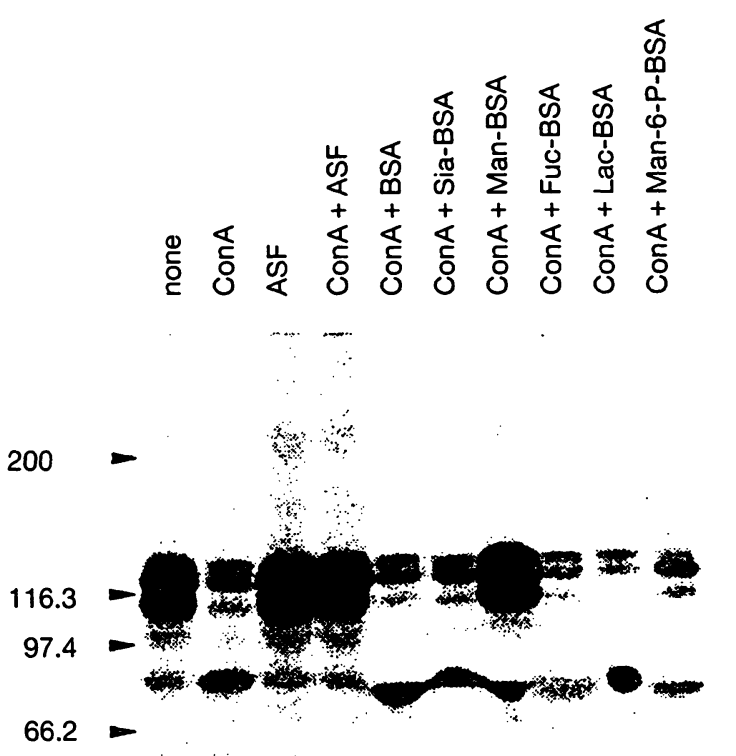

45
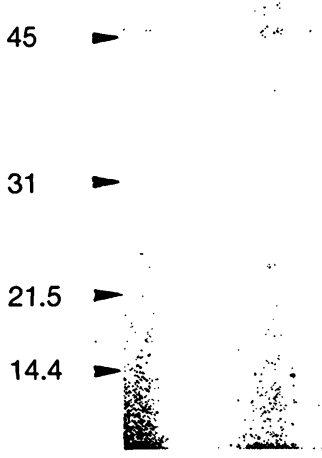

Fig. 2. Effects of asialofetuin and different neoglycoproteins on the concanavalin A action on adenylylation and on the phosphodiesterase catalytic intermediate.

Crude plasma membranes ( $90 \mu \mathrm{g}$ of protein) were incubated in the assays at $37^{\circ} \mathrm{C}$ for $5 \mathrm{~min}$ in $100 \mu \mathrm{l}$ of a medium containing $20 \mathrm{~mm}$ Na-Hepes (pH 7.4), $0.1 \%$ (w/v) Triton X-100, $10 \mu \mathrm{M}[\alpha-$ $\left.{ }^{32} \mathrm{P}\right] \mathrm{ATP}$ and, where indicated, $500 \mu \mathrm{g} \times \mathrm{m} l^{-1}$ concanavalin A (ConA), $1 \mathrm{mg} \times \mathrm{ml}^{-1}$ asialofetuin (ASF), $1 \mathrm{mg} \times \mathrm{m} l^{-1}$ mannose-BSA (Man-BSA), $1 \mathrm{mg} \times \mathrm{ml}^{-1}$ mannose-6-phosphateBSA (Man-6-P-BSA), $1 \mathrm{mg} \times \mathrm{m}^{-1}$ lactose-BSA (Lac-BSA), $1 \mathrm{mg} \times \mathrm{m} l^{-1}$ fucose-BSA (Fuc-BSA), $1 \mathrm{mg} \times \mathrm{ml}^{-1}$ sialic acidBSA (Sia-BSA), or $1 \mathrm{mg} \times \mathrm{m} l^{-1}$ bovine serum albumin (BSA). The neoglycoproteins or asialofetuin were added to the assay system before the lectins. The reaction was stopped with $10 \%$ $(\mathrm{w} / \mathrm{v})$ ice-cold trichloroacetic acid and the precipitated proteins processed for electrophoresis and autoradiography as described in Materials and Methods. A representative autoradiograph is presented. 
the concanavalin A-agarose column. In Fig. 3 the patterns of labeling obtained with $\left[\alpha-{ }^{32} \mathrm{P}\right] \mathrm{ATP}$ (panel A), and $\left[\gamma-{ }^{32} \mathrm{P}\right]$ ATP (panel B) are compared.

It can be seen that the four major polypeptides (130kDa. 120-kDa. 110-kDa, and 100-kDa) are adenylylated (labeling by $\left.\left[\alpha-{ }^{32} \mathrm{P}\right] \mathrm{ATP}\right)$, not only in their membrane-bound form (panel A, lane 1), but also in thei: solubilized form obtained from the concanavalin Aagarose column (panel A, lane 2). We performed the adenylylation assays of the polypeptides with the mannose-eluted fractions after they were eluted from the concanavalin A-agarose column. Therefore, it is possible that the polypeptides under study are undergoing an autoadenylylation process. Alternatively, we

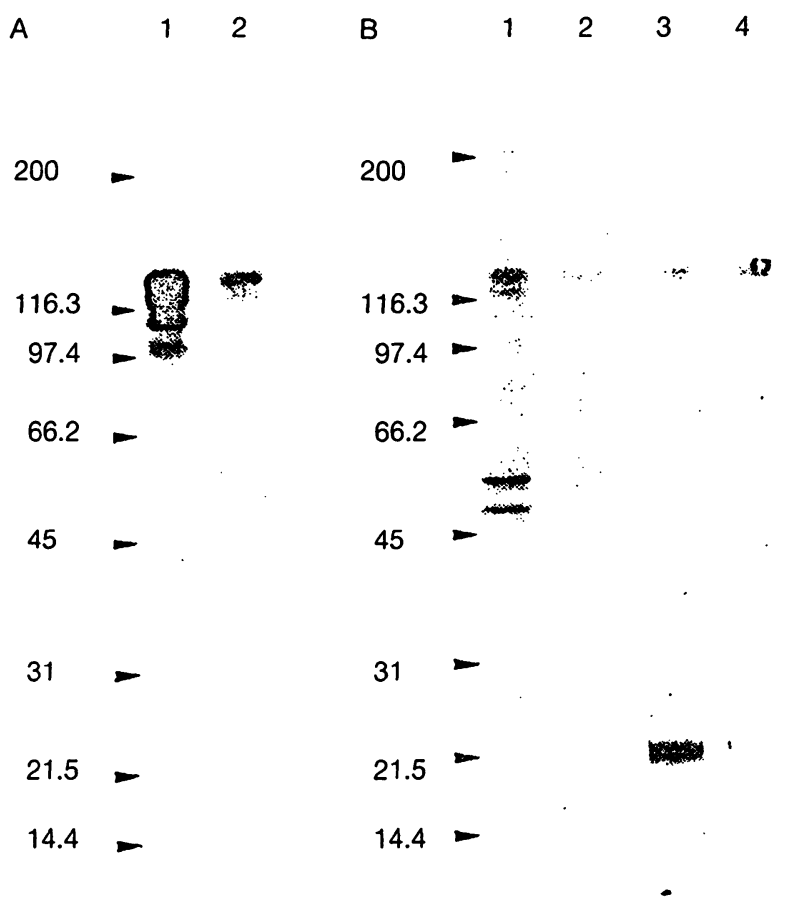

Fig. 3. A protein kinase activity is present in the concanavalin A-agarose-cluted fractions.

(Panel A) Purified plasma membranes ( $40 \mu \mathrm{g}$ of protein) (lane 1), and the peak from the mannose-eluted fractions from the concanavalin A-agarose column $(80 \mu l)$ (lane 2) were assayed at $37^{\circ} \mathrm{C}$ for $5 \mathrm{~min}$ in $200 \mu \mathrm{l}$ of a medium containing $15 \mathrm{~mm} \mathrm{Na}$ Hepes (pH 7.4). I mm EDTA, and $10 \mu \mathrm{M}\left[\alpha{ }^{-32}\right.$ P]ATP. (Panel B) Purificd plasma membranes ( $40 \mu \mathrm{g}$ of protein) (lane 1 ), and the pcak from the mannose-eluted fractions from the concanavalin A-agarose column $(80 \mu \mathrm{l})$ (lanes 2 to 4 ) were assayed at $37^{\circ} \mathrm{C}$ for $1 \mathrm{~min}$ in $100 \mu \mathrm{l}$ of a medium containing $15 \mathrm{~mm} \mathrm{Na}-\mathrm{Hepes}$ (pH 7.4). $50 \mu \mathrm{g} \times \mathrm{ml}^{-1}$ histone (lane 3 only), $100 \mu \mathrm{g} \times \mathrm{m} l^{-1}$ poly(Glu:Tyr) (lane $t$ only), and $10 \mu \mathrm{M}\left[\gamma^{3}{ }^{32} \mathrm{P}\right] \mathrm{ATP}$. The reactions were stopped with $10 \%(\mathrm{w} / \mathrm{v})$ of ice-cold trichloroacetic acid, and the precipitated protein processed for electrophoresis and autoradiography as described in Materials and Methods. A representative autoradiograph is presented. Similar results were obtained when the assays were carried out in the presence of $6 \mathrm{mM} \mathrm{MgCl}$. may have copurified by the concanavalin A-agarose column the polypeptides that can be adenylylated and an exogenous adenylylation system, responsible for the adenylylation of these polypeptides.

Fig. 3 shows that the four polypeptides under study are also phosphorylated (labeling by $\left[\gamma_{-3}-\mathrm{P}\right] \mathrm{PTP}$ ) in their membrane-bound form (panel B, lane 1). In their solubilized form eluted with mannose from the concanavalin A-agarose column, however, the only labeled band observed corresponds to the $130-\mathrm{kDa}$ polypeptide (panel B, lane 2). We can not exclude that the other lower molecular mass polypeptides could be detected by prolonged exposure of the film or may be phosphorylated under other experimental conditions. However, these experiments suggest that the phosphorylation systems for the $120-\mathrm{kDa}, 110$ $\mathrm{kDa}$, and 100-kDa polypeptides on one hand, and the phosphorylation system for the $130-\mathrm{kDa}$ polypeptide on the other, are different.

We also show that the fractions eluted from the concanavalin A-agarose column are able to phosphorylate exogenous substrates, such as histones (panel B, lane 3). However, phosphorylation of a polymer of glutamic acid and tyrosine was not detected (panel B, lane 4). Phosphorylated poly(Glu:Tyr) should have migrated in these gels as a broad smear approximately between $120-\mathrm{kDa}$ and $25-\mathrm{kDa}$, as demonstrated by phosphorylation of this co-polymer by an epidermal growth factor receptor preparation (results not shown). In over-exposed autoradiographs, however, we detected trace levels of phosphorylated poly(Glu:Tyr). Nevertheless, it is apparent that the fractions eluted from the concanavalin A-agarose column contain a protein kinase activity that does not appear to be significantly directed to tyrosine residues.

\section{Mistletoe and bovine heart lectins bind to different liver plasina membrane glycoproteins}

The mistletoe and bovine heart lectins are known to interact with $\beta$-galactoside-containing glycoproteins. However, other types of interactions of these lectins with their target proteins, including protein-protein interactions are not excluded. Indeed, the mammalian lectin has been described as a cell growth regulator, and as TGF- $\gamma 2$, independent of its carbohydrate-binding activity, underscoring its bifunctional nature ${ }^{[31.32]}$. The patterns of polypeptides eluted with lactose from two columns prepared by covalent binding of each lectin to a matrix are shown in Fig. 4. They clearly show that both lectins interact with different glycoproteins from liver plasma membrane. Identical monosaccharide specificity of two lectins is thus not necessarily an indication of identical affinities to tissue ligands. 


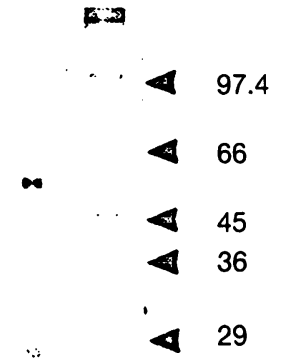

14.3

a b

Fig. 4. Mistletoe and bovine heart lectins have different targets for liver plasma membrane polypeptides.

Polypeptides isolated from the $14-k D a$ bovine heart lectin affinity chromatography column (lane a). and from the mistletoc lectin I affinity chromatography column (lane b) upon elution with lactose as described in Materials and Methods. The samples were analysed by polyacrylamide gel electrophoresis in the presence of SDS, followed by silver staining.

\section{Neoglycoproteins and asialofetuin fail to protect the adenylylation process from the inhibitory action of mistletoe and bovine heart lectins}

Due to the proven ability of the mammalian lectin to interact with proteins independently of its capacity to act as sugar receptor, we tested the above-mentioned neoglycoproteins, as well as asialofetuin, for their possible protective effects on the mistletoe and bovine heart lectins-induced inhibition of adenylylation. Remarkably, none of these neoglycoproteins, nor asialofetuin, prevent the inhibition of the adenylylation produced by mistletoe lectin or bovine heart lectin (results not shown). In all cases both lectins were still able to inhibit the adenylylation of the plasma membrane glycopolypeptides even in the presence of $1 \mathrm{mg} \times \mathrm{ml}^{-1}$ of the neoglycoproteins or of asialofetuin in the assay system.

To corroborate these results with the neoglycoproteins, we have assayed these lectins in the absence and presence of galactose, mannose and several free $\beta$-galactosides, as well as $\alpha$-galactosides, up to a concentration of $20 \mathrm{~mm}$.

Lactose, melibiose, 3- $\beta$-Gal-Ara, 4- $\beta$-Gal-Fru, 4- $\beta$ Gal-Man, $6-\beta-\mathrm{Gal}-\mathrm{Gal}$, and $4-\alpha-\mathrm{Gal}-\mathrm{Gal}$, as well as galactose and mannose fail to prevent the inhibitory action of mistletoe lectin or bovine heart lectin (results not shown). Overall, these experiments support our previous results, in which the neoglycoprotein- containing lactose residues do not prevent the inhibitory action of these lectins.

There are two main possible explanations of these results: i) the affinity of these lectins for the $\beta$-galactoside residues and their unknown subterminal extension of the target proteins and/or the adenylylation system(s) is far higher than for the lactose-containing neoglycoprotein, free lactose or the other free $\beta$ galactosides used: or alternatively ii) we are dealing with protein-protein interactions. We can exclude that the simple sugars used could not compete for lectins bound to more complex protein carbohydrate ligands since it has been demonstrated that galactose effectively reduces binding of the lectins to the carbohydrate chains of asialofetuin ${ }^{[33]}$.

\section{The phosphorylation of the plasma membrane} glycoproteins that can be adenylylated is also inhibited by lectins but to a lesser extent than adenylylation

Phosphorylation of the proteins that are adenylylated is better observed in highly purified plasma membrane fractions. Therefore, we used these fractions to perform phosphorylation experiments. Fig. 5 presents the effect of mistletoe lectin and bovine heart lectin on the phosphorylation (label by $\left[\gamma^{32} \mathrm{P}\right] \mathrm{ATP}$ ) of proteins in a further purified plasma membrane fraction (panel B). The phosphorylation of the $130-\mathrm{kDa}$, $120-\mathrm{kDa}, 110-\mathrm{kDa}, 100-\mathrm{kDa}$ polypeptides that can be adenylylated, and the phosphorylation of the $86-\mathrm{kDa}$ phosphodiesterase are slightly inhibited by both lectins. As a control, we present in panel A of the same figure the effect of identical concentrations of both lectins on the adenylylation of the polypeptides under study. These lectins inhibit the adenylylation of these polypeptides far more efficiently than their phosphorylation. Furthermore, these lectins do not significantly affect the phosphorylation of other proteins observed in crude membrane fractions (results not shown).

The levels of phosphorylation of the 130-kDa, 120$\mathrm{kDa}, 110-\mathrm{kDa}$ and 100-kDa plasma membrane polypeptides that can be adenylylated, and the phosphorylation of the $86-\mathrm{kDa}$ phosphodiesterase are inhibited by progressively higher concentrations of different lectins. In Fig. 5, panel $\mathrm{C}$ the inhibitory action of mistletoe lectin (open triangles), bovine heart lectin (filled triangles), and concanavalin A (open circles) are presented. We calculated $K_{\mathrm{i}}$ values for mistletoe and bovine heart lectins of 80 and $100 \mu \mathrm{g} \times \mathrm{m} l^{-1}$, respectively, from these plots. In contrast, a concentration of concanavalin A as high as $500 \mu \mathrm{g} \times \mathrm{m} l^{-1}$ only inhibits the phosphorylation of these polypeptides by $25 \%$. 

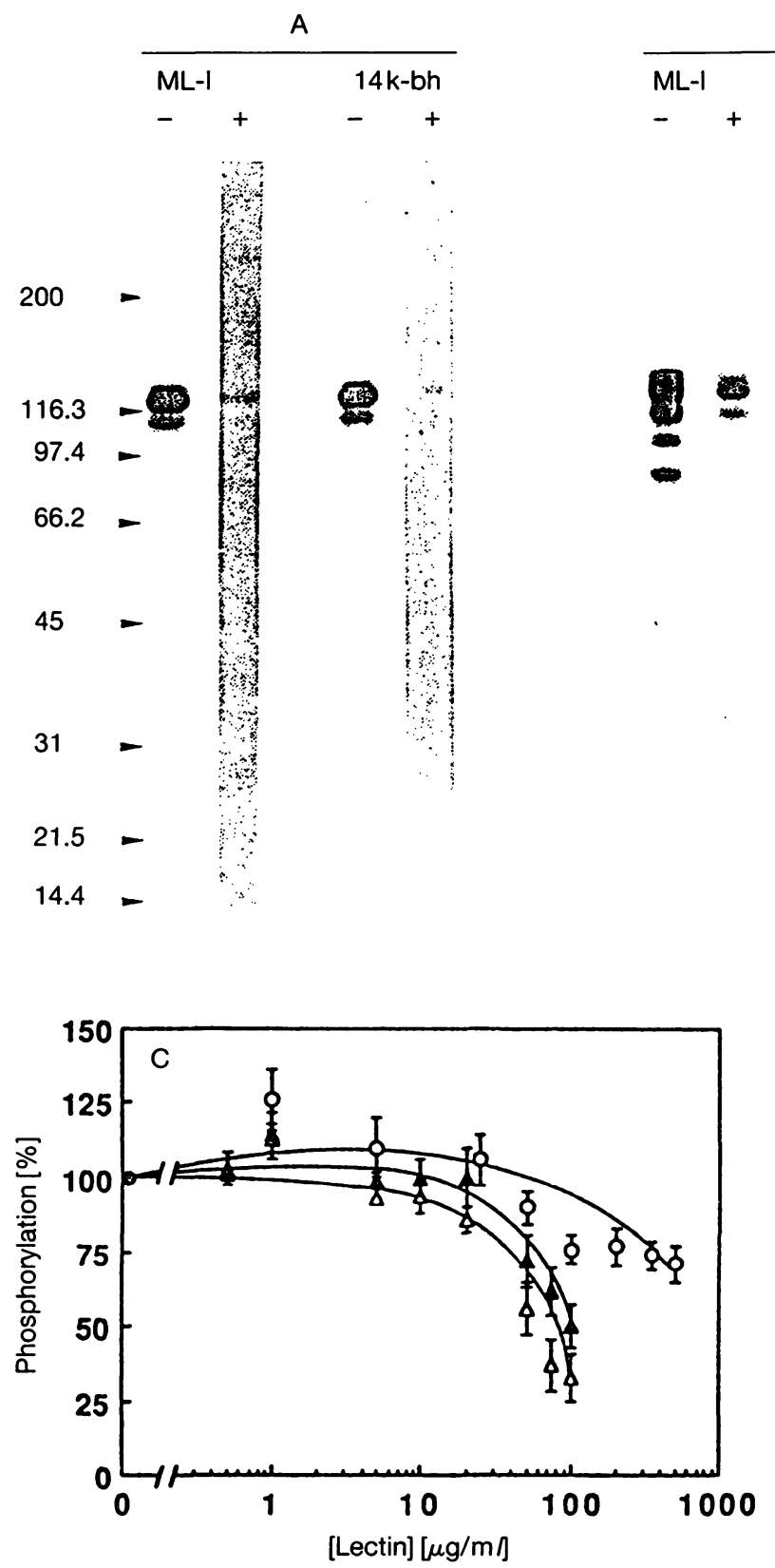

We must emphasize that we do not yet know whether the adenylylation system(s) is(are) distinct from the target adenylylated proteins. Similarly, it is not clear whether all observed phosphorylation in these proteins are autophosphorylation processes or whether an exogenous protein kinase(s) is(are) involved. Therefore, the chain of events in the mechanism of action of lectins on the adenylylation and phosphorylation of the plasma membrane polypeptides under study can at present not be explained at a molecular level.

The finding that the adenylylation and the phosphorylation of these polypeptides are not equally inhibited by lectins, as inferred by dissimilar $K_{\mathrm{i}}$ values, suggests that the systems responsible for both posttransla-
B

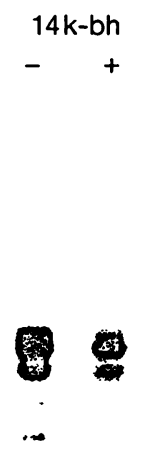

Fig.5. Comparative effects of lectins on the adenylylation and phosphorylation of the 130-kDa. $120-k D a .110-k D a$ and $100-k D a$ polypeptides that can be adenylylated, and on the phosphorylation of the 86-kDa phosphodiesterase.

(Panel A) Crude plasma membranes $(40 \mu \mathrm{g}$ of protein) were assayed at $37^{\circ} \mathrm{C}$ for $5 \mathrm{~min}$ in $100 \mu \mathrm{l}$ of a medium containing $15 \mathrm{~mm}$ Na-Hepes ( $\mathrm{pH} 7.4) \cdot 0.1 \%$ $(w / v)$ Triton X-100,10 $\mu \mathrm{M}\left[\alpha-{ }^{32} \mathrm{P}\right] \mathrm{ATP}$, and in the absence $(-)$ or presence $(+)$ of $100 \mu \mathrm{g} \times \mathrm{m} l^{-1}$ mistletoe lectin I (ML-I), or $100 \mu \mathrm{g} \times \mathrm{m} l^{-1}$ bovine heart 14-kDa lectin (1+k-bh). (Panel B) Purified plasma membranes $(92 \mu \mathrm{g}$ of protein) were assayed for $1 \mathrm{~min}$ at $37^{\circ} \mathrm{C}$ in $100 \mu \mathrm{l}$ of a medium containing $15 \mathrm{~mm}$ Na-Hepes (pH 7.4), $0.1 \%$ (w/v) Triton X-100. $10 \mu \mathrm{M}\left[\gamma_{-}{ }^{32} \mathrm{P}\right] \mathrm{ATP}$, and in the absence $(-)$ or presence $(+)$ of the indicated lectins as above. The reaction was stopped with $10 \%$ (w/v) ice-cold trichloroacetic acid, and the precipitated proteins processed for electrophoresis and autoradiography as described in Materials and Methods. Representative autoradiographs are presented. (Panel C). A plot representing the action of different concentrations of lectins on the average phosphorylation of the $130-k D a, 120-k D a, 110-k D a$ and $100-k D a$ adenylylable polypeptides and the phosphorylation of the $86-\mathrm{kD}$ a phosphodiesterase is presented. The assays were carried out as above with further purified plasma membrane fractions, except for the following amount of membrane proteins: $28 \mu \mathrm{g}$ (open circles), $28 \mu \mathrm{g}$ (open triangles), $92 \mu \mathrm{g}$ (filled triangles), and the indicated concentrations of concanavalin $\mathrm{A}$ (open circles), mistletoe lectin I (open triangles), or bovine heart $14-\mathrm{kDa}$ lectin (filled triangles). tional modifications of these plasma membrane proteins are indeed different. Furthermore, it suggests that these lectins inhibit the two processes by different mechanisms.

Nevertheless, it is reasonable to keep in mind that the adenylylation-deadenylylation system and/or the polypeptides that can be adenylylated (if different) from the plasma membrane could be physiological targets for the mammalian lectin. Since triggering responses by a lectin may require occupation of other structures in addition to carbohydrate-binding sites, as demonstrated for wheat germ lectin-induced synthesis of decay-accelerating factor in human endothelial cells ${ }^{[3+]}$, description of such ligands will be helpful to clarify interactions of a potent lectin within the 
membrane. Thus, further work should be done to elucidate whether or not the interaction of lectins with the adenylylation and phosphorylation system(s) involved in the posttranslational modification of these plasma membrane glycoproteins belongs to the physiological steps involved in the still elusive mechanism of signal transduction by these carbohydrate-binding proteins.

The expert technical assistance of K.P. Hellmann is gratefully acknowledged. This work was supported in part by grants (to A.V.) from the Dirección General de Investigación Cientifica y Técnica (PB 89-0079). and from the Consejería de Educación de la Comunidad de Madrid (C174-90 and 366/92) Spain, grants (to H.-J.G.) from the Dr: M. Scheel-Stiftung fiir Krebsforschung and the BMFT program Alternative Methoden der Krebsbekämpfung. Germany, and the Acciones Integradas (42A) beween Germany and Spain (to H.-J.G. and A.V.). E.S.J. is the recipient of a predoctoral fellowship from the Departamento de Educación. Universidades e Investigación del Gobierno Vasco.

\section{References}

I Liener. I.E.. Sharon. N. \& Goldstein. I.J. (eds.). (1986) The Lectins. Properties, Function and Applications in Biology' and Medicine, Academic Press. New York.

2 Olden. K. \& Parent. J.B. (eds.). (1987) Vertebrate Lectins, Van Nostrand Reinhold Co., New York.

3 Gabius, H.-J. \& Gabius, S. (eds). (1991) Lectins and Cancer, Springer-Verlag, Heidelberg.

4 Lis, H. \& Sharon, N. (1986) Annu. Rev. Biochem. 55, $35-$ 67.

5 Gabius, H.-J. (1991) Biochim. Biophys. Acta 1071. 1-18.

6 Barondes, S.H. (1984) Science 223, 1259-1264.

7 Sharon. N. \& Lis. H. (1987) Trends Biochem. Sci. 12, 488491.

8 Calvo, F.O. \& Ryan, R.J. (1985) Biochemistry 24, 19531959.
9 Nagai, Y. \& Tsuji. S. (1988) in Lectins and Glycoconjugates in Oncology' (Gabius. H.-J. \& Nagel, G.A., eds.) pp. 5966. Springer-Verlag, Heidelberg.

10 Sairam, M.R. (1989) FASEB J. 3, 1915-1926.

11 San José, E., Benguría, A. \& Villalobo, A. (1990) J. Biol. Chem. 265, 20653-20661.

12 Brown, A.E., Lok, M.P. \& Elovson, J. (1976) Biochim. Biophys. Acta 426, 418-432.

13 Church, J.G., Ghosh, S., Roufogalis, B.D. \& Villalobo. A. (1988) Biochem. Cell Biol. 66. 1-12.

14 Gabius. H.-J. \& Bardosi. A. (1991) Prog. Histochem. Cytochem. 22, 1-63.

15 Gabius. H.-J. (1990) Anal. Biochem. 189, 91-94.

16 Powell, J.T. \& Whitney, P.L. (1984) Biochem. J. 223, 769776.

17 Redinbaugh. M.G. \& Campbell, W.H. (1985) Anal. Biochem. 147, 144-147.

18 Gabius, H.-J., Wosgien, B., Hendrys, M. \& Bardosi, A. (1991) Histochemistry 95, 269-277.

19 Laemmli, U.K. (1970) Nature (London) 227, 680-685.

20 Blum, H., Beier, H. \& Gross, H.J. (1987) Electrophoresis 8, 93-99.

21 Lowry, O.H., Rosebrough, N.J., Farr, A.L. \& Randall, R.J. (1951) J. Biol. Chem. 193. 265-275.

22 Shapiro. B.M.. Kingdon. H.S. \& Stadtman, E.R. (1967) Proc. Natl. Acad. Sci. USA, 58, 642-649.

23 Shapiro. B.M. \& Stadtman, E.R. (1968) J. Biol. Chem. 243, 3769-3771.

24 Kustu, S., Hirschman, J., Burton, D., Jelesko, J. \& Meeks, J.C. (1984) Mol. Gen. Genet. 197, 309-317.

25 Kustu, S., Hirschman, J. \& Meeks, J.C. (1985) Curr. Top. Cell. Regul. 27, 201-213.

26 Niles, E.G. \& Westhead, E.W. (1973) Biochemistry 12. 1723-1729.

27 Chelala, C.A., Hirschbein, L. \& Torres, H.N. (1971) Proc. Natl. Acad. Sci. USA, 68. 152-154.

28 Caron. M., Bladier. D. \& Joubert, R. (1990) Int. J. Biochem. 22, 1379-1385.

29 Harrison, F.L. (1991) J. Cell Sci. 100, 9-14.

30 Barondes, S.H. (1988) Trends Biochem. Sci. 13, 480-482.

31 Wells, V. \& Malluci, L. (1991) Cell 64, 91-97.

32 Yamaoka, K., Ohno, S., Kawasaki, H. \& Suzuki, K. (1991) Biochem. Biophys. Res. Commun. 179, 272-279.

33 Lee, R.T., Gabius, H.-J. \& Lee, Y.C. (1992) J. Biol. Chem. 267, 23722-23727.

34 Bryant, R.W., Granzow, C.A., Siegel, M.I., Egan, R.W. \& Billah, M.M. (1991) J. Immunol. 147, 1856-1862.

E. San José, E. Villalobo and A.Villalobo*, Instituto de Investigaciones Biomédicas, CSIC,

Arturo Dupericr 4, E-28029 Madrid. Spain:

H.-J. Gabius, Institut für Pharmazeutische Chemie der Universität, Abteilung Glykobiochemie und Angewandtc

Tumorlektinologie,

MarbacherWeg 6. W-3550 Marburg, Germany.

* To whom correspondence should be sent. 
